\title{
REPENSANDO AS ANISTIAS DE USO E OCUPAÇÃO DO SOLO EM SÃO PAULO
}

\author{
Rosane Segantin KePPKe* \\ *Doutora em Arquitetura e Urbanismo pela Faculdade de Arquitetura e Urbanismo da Universidade \\ de São Paulo, mestre em Administração Pública pela Fundação Getúlio Vargas, e especialista em desen- \\ volvimento urbano da Prefeitura do Município de São Paulo. Contato: rkeppke@prefeitura.sp.gov.br
}

\section{RESUMO}

A regularização urbanística é um dos fundamentos do Estatuto da Cidade. Em São Paulo esta é uma prática de gestão centenária, tributária do fenômeno da "urbanização desordenada". Este artigo expõe seu histórico de anistias e propõe modelos que incorporem o princípio da compensação urbanístico-ambiental, a fim de que a cidade possa regularizar seus passivos sem preterir a sustentabilidade, tornando-se mais verde.

Palavras-chave: Uso e ocupação do solo - regularização fundiária e edilícia - passivos urbanístico-ambientais - sustentabilidade - responsabilidade socioambiental

\section{RETHINKING AMNESTIES OF USE AND OCCUPATION OF LAND IN SÃO PAULO}

\begin{abstract}
The urban regularization is one of the main points of the City Statute. In São Paulo this is a centennial practice of management, derived from the phenomenon of "unplanned urbanization". This article exposes the history of amnesties and proposes models that incorporate the principle of urban-environmental compensation, so that the city is able to regulate its liabilities without omitting sustainability, becoming greener.
\end{abstract}

Keywords: Use and land cover; land and edificial regularization; liabilities urban-environment sustainability, socio-environmental responsibility 


\section{INRODUÇÃO: O Estatuto da Cidade e o fomento à política de regularização}

O Estatuto da Cidade (Lei federal n. 10.257, de 10 de julho de 2001) brindou o movimento da reforma urbana e os municípios brasileiros com instrumentos urbanísticos indutores de governança local. Nas regiões metropolitanas, as zonas especiais de interesse social tendem a ser os instrumentos que ocupam as maiores extensões nos planos diretores locais, seguidos da outorga onerosa do direito de construir, geralmente associada às operações urbanas consorciadas. As primeiras, de caráter inclusivo, visam à universalização da urbanidade, fazendo-a chegar aos confins das periferias e bolsões de desigualdades. As segundas tentam dividir o ônus dos investimentos infraestruturais que convergem com os interesses do mercado imobiliário. Assim colocada, esta dualidade reflete o dilema multifocal do Planejamento Urbano de agregar urbanização de vanguarda, por este lado e, pelo outro lado, resgatar o que ficou para trás, reurbanizar no sentido de tornar urbano aquilo que precariamente o era, ao mesmo tempo em que deve ouvir as demandas de todos os segmentos sociais e orientar-se pelos princípios da sustentabilidade.

O maior desafio das cidades brasileiras, hoje, é construir o futuro a partir dos seus passivos urbano-ambientais, para além da prática da simples regularização. Neste sentido, o Estatuto da Cidade ainda é uma resposta insuficiente, cabendo ao Poder Executivo e ao Parlamento de todas as instâncias de governo prospectar instrumentos de reparação de danos, mitigação e compensação de impactos da "urbanização desordenada" que as desqualifica.

Neste contexto cabe colocar o emblemático caso da cidade de São Paulo, no que diz respeito ao seu histórico de anistias às infrações de parcelamento, uso e ocupação do solo. O tema ganha proeminência com a lei municipal $n^{0} 15.499$, de 7 de dezembro de 2011, que institui o Auto de Licença de Funcionamento Condicionado de atividades instaladas em edificações irregulares, de vigência provisória, que está gerando pressões por uma nova anistia a fim de torná-las regulares sem ônus adicionais ou sanções pelas infrações cometidas, a exemplo de anistias passadas.

\section{2. "DÉJÀ VU"}

São Paulo adotou a regularização como modelo de gestão urbana. Desde as primeiras leis urbanísticas, criadas na virada dos séculos XIX e XX, o poder público tem recorrido à prática de "legislar por um lado e anistiar por outro" (GROSTEIN, 1987, p. 121). 
A primeira lei de arruamentos (lei municipal n. 1666 de 26 de março de 1913) logo foi sucedida por uma sequência de oficialização (regularização) de vias em massa que ocorreram nos anos de 1914, 1916, 1934, 1953, 1955, 1962, 1963, 1972, 1973, 1974.

O Código Arthur Saboya (lei municipal n. 3.427 de 19 de novembro de 1929) foi o primeiro a juntar num único instituto legal as posturas, o arruamento, o parcelamento, as edificações e até mesmo o instrumento de regularização de infrações passadas bem como aquelas que porventura viessem a ocorrer. Já em 1931, o urbanista Anhaia Mello lamentava que a "cidade clandestina era maior do que a oficial" (apud op. cit., p. 154).

O primeiro plano diretor (lei municipal n. 7.688 de 30 de dezembro de 1971) e o primeiro zoneamento da cidade como um todo (lei municipal n. 7.805 de 1 de novembro de 1972) constituíram o marco estruturante para o futuro e o marco regularizador para o passivo instalado, garantindo direito a usos e atividades não conformes que comprovassem anterioridade àquela data.

Em 1979 foi criada a SERLA - Supervisão Especial de Regularização de Loteamentos e Arruamentos, a fim de liquidar a demanda de regularização fundiária acumulada até então, em caráter "ex officio", isto é, promovida pelo Poder Público. Enquanto eram procurados e julgados criminalmente os loteadores, sem o êxito esperado, o ônus dos investimentos urbanísticos acabou sendo socializado com todos os contribuintes (cf. op. cit., p. 494).

Sobre o esteio do plano diretor de 1971, a cidade expandiu-se até o atual plano diretor (lei municipal n. 13.430 de 13 de setembro de 2002), perpetuando, contudo, a recorrência sistemática de anistias edilícias e fundiárias, a saber, pelas leis municipais n. 10.199 de 3 de dezembro de 1986, lei n. 11.522 de 3 de maio de 1994 (edilícia), lei n. 11.775 de 29 de maio de 1995 (fundiária), lei n. 13.428 de 10 de setembro de 2002 (fundiária), lei n. 13.558 de 14 de abril de 2003 (edilícia), as duas últimas acompanhando o plano diretor vigente.

A propósito, para as anistias de 1994 e 2003, o Ministério Público impetrou ação civil pública contra as irregularidades de parcelamento do solo e aos casos de não conformidade às zonas de uso, sinalizando que, dali em diante, as anistias já não poderiam ser amplas, gerais e irrestritas como as ocorridas no passado.

Até então, a prática de regularização contemplava a propriedade urbana, mas o Estatuto da Cidade, complementado pela Medida Provisória $n^{\circ} 2.220$ de 4 de setembro 
de 2001, introduziu a desafetação de áreas de uso comum do povo para a concessão de uso especial para fins de moradia, em outras palavras, para regularizar a posse e reurbanizar favelas, o que se tornou a política nacional de habitação de interesse social para as regiões metropolitanas.

\section{POR TRÁS DA “URBANIZAÇÃO DESORDENADA"}

Há um mito que restringe a urbanização desordenada à falta de planejamento, todavia, em que pese a ausência de um plano fundador a exemplo de Brasília, à cidade de São Paulo nunca faltaram planos e leis, haja vista a amostra retro mencionada. Dois fatores superaram a falta de planejamento: a falta de política habitacional e a falta de fiscalização, e ambos estão fortemente correlacionados (KEPPKE, 2007).

Habitação, ou a falta dela foi a lacuna crucial do fenômeno exponencial da urbanização paulistana nos primeiros três quartos do século $X X$, que se deu com a industrialização. A lei do inquilinato, o Sistema Financeiro da Habitação e os conjuntos habitacionais de massa foram políticas escassas no tempo, na satisfação da demanda, e foram fartos em efeitos perversos e impotência para dar conta dos segmentos excluídos (BONDUKI, 1998; SAMPAIO, 2002). Segundo Keppke (op. cit.), na impossibilidade de oferecer provisão direta, o poder público tratou de facilitar a aquisição de terrenos e a autoconstrução da casa própria, estabelecendo uma legislação pautada em parâmetros urbanísticos mínimos: lotes mínimos, recuos mínimos, dimensões mínimas de compartimentos.

Ao longo do tempo, na tentativa de promover o acesso à propriedade urbana, estes mínimos foram se tornando cada vez menores. A título de exemplo, $300 \mathrm{~m} 2$ era a área do lote mínimo instituído pela lei municipal n. 2.611 de 20 de junho de 1923. Com o advento da lei federal de parcelamento do solo (lei n. 6.766 de 19 de dezembro de 1979), São Paulo adotou como regra o "meio lote" de 125 m2 (lei municipal n. 9.413 de 30 de dezembro de 1981). Lotes ainda menores tornaram-se possíveis, tais como as residências geminadas com terreno de $68 \mathrm{~m} 2$ (lei municipal n. 8.266 de 20 de junho de 1975) e as vilas residenciais, onde se admite a fração de 62,5 m2 (lei municipal n. 11.605 de 12 de julho de 1994), portanto equivalente a um quarto do lote mínimo federal (KEPPKE E SILVA, 2012 ).

Mínimas também eram as contrapartidas de infraestrutura exigidas pelos loteadores, a fim de que não onerassem custos para os adquirentes (lei federal n. 6.766 de 19 de 
dezembro de 1979). Contudo, o preço do solo urbano não se tornou acessível, nem mesmo na periferia. Aos excluídos restou ocupar ilegalmente as áreas públicas do sistema de áreas verdes e áreas institucionais dos loteamentos, sob as "vistas grossas" do poder público.

Certamente os ganhos fundiários propiciados pela legislação minimalista foram capturados nas transações imobiliárias. Abrindo parêntesis, segundo a Economia Clássica, o comportamento especulativo do "homo economicus" é inerente à lei da oferta e da demanda, e independe de estrato social, inclusive pode ser observado nas transações informais realizadas em favelas e loteamentos clandestinos (KEPPKE, 2007, p. 46).

Fiscalização, ou a falta dela foi a questão central da proliferação das irregularidades. Segundo Keppke (op. cit.), Keppke e Silva (2012), a omissão fiscal foi um fenômeno crescente no tempo (gráfico 1) e no espaço, disseminada em todo território paulistano, porém tanto maior nos distritos e subprefeituras caracterizadas pela exclusão social (mapa 1).

\section{MULTAS CADASTRADAS}

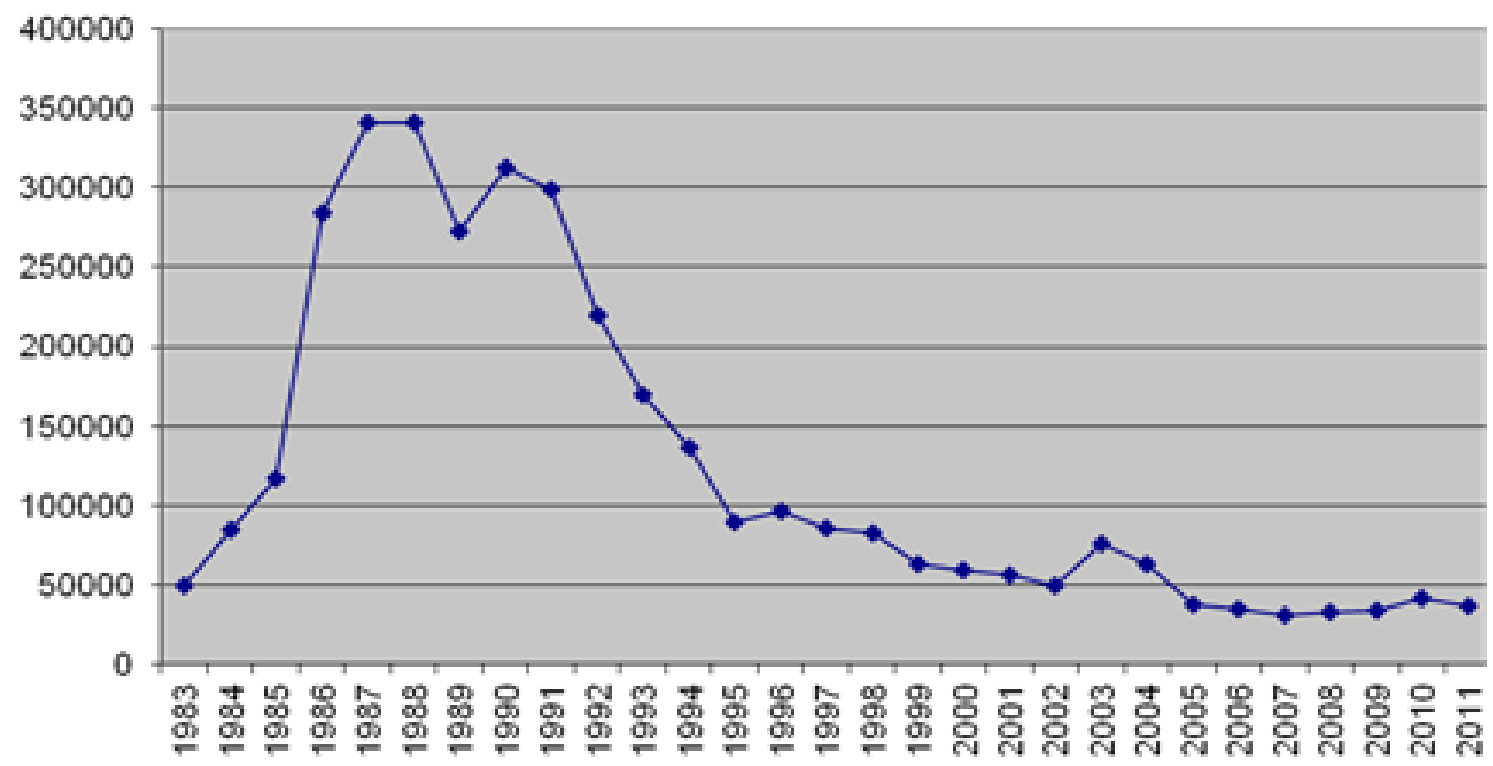

Gráfico 1 - Multas cadastradas. Fonte: PRODAM/ CUBOS/SIMPROC/FISC, 2011

O Gráfico 1 é resultante do cadastro de multas por infrações de parcelamento, uso e ocupação do solo ao longo dos anos, a partir da informatização dos processos fiscalizatórios, em 1983. Nota-se que a produção fiscal teve picos, em determinados momentos, para depois cair numa curva descendente que se mantém há sucessivas 
gestões. Tal apatia é uma evidência de que a Fiscalização não é pauta prioritária na agenda pública (KINGDON, 1994), pelo contrário, sua impopularidade e vulnerabilidade a distorções e corrupção tornaram-na objeto de ordens de serviço pontuais ou temáticas vinculadas às demandas do Ministério Público, da Ouvidoria Geral, do Sistema de Atendimento ao Cidadão e da alta direção, esta última pressionada pela mídia e pela sociedade organizada (KEPPKE, 2007).

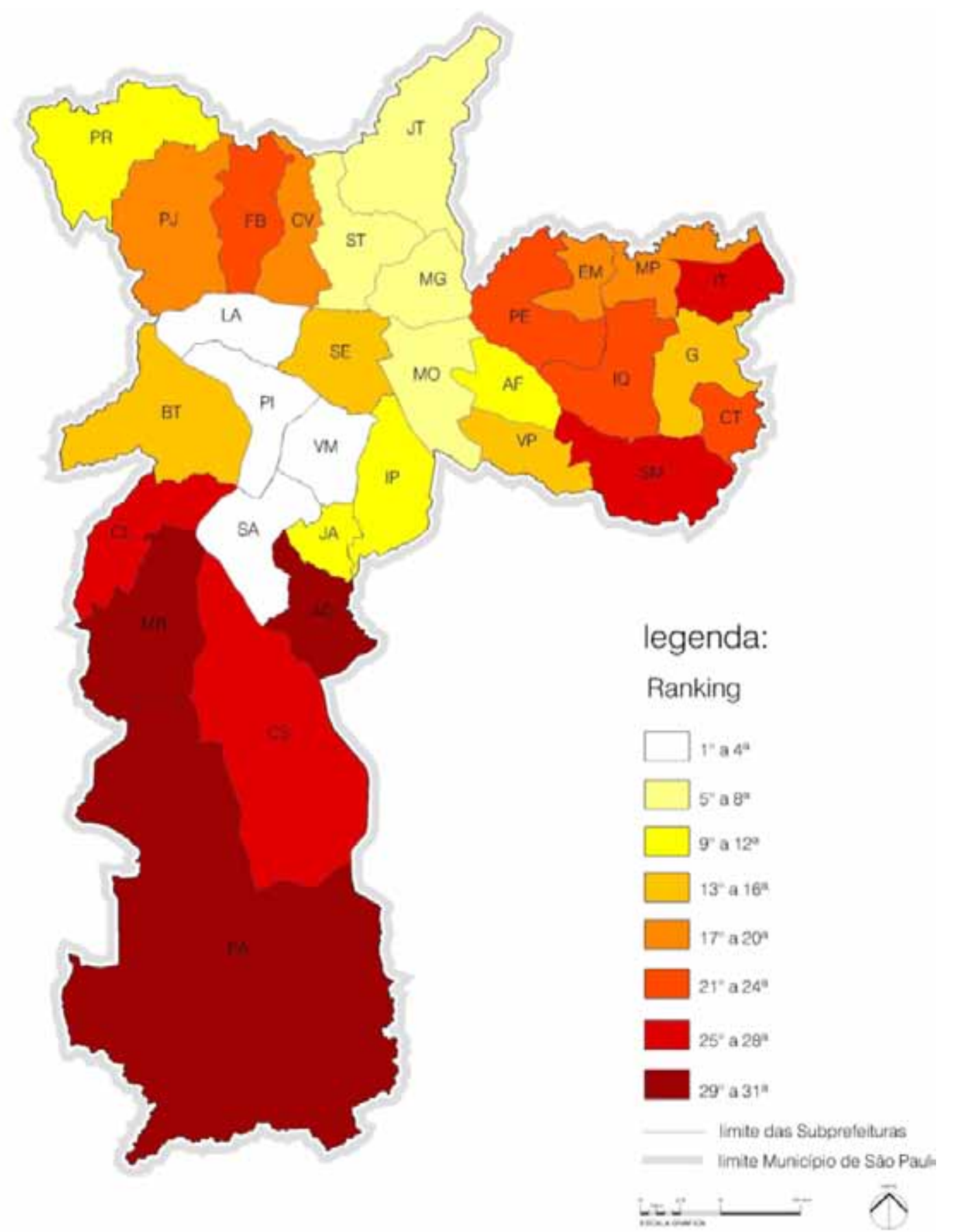

Mapa 1 - Indicador Geral de Controle de Uso e Ocupação do Solo. Fonte: KEPPKE, 2007, p. 194 
O Mapa 1 resultou de análise multivariada que regionalizou as informações da oferta, da demanda e das condições de contorno no controle de parcelamento, uso e ocupação do solo. Formulou-se a partir do Perfil Socioambiental do município (São Paulo/ Cidade, 2002), agregando dados do Sistema de Atendimento ao Cidadão - SAC, Ouvidoria Geral, Sistema Municipal de Processos - SIMPROC e Secretaria de Coordenação das Subprefeituras, entre outras fontes principais (KEPPKE, 2007, p. 181).

O Mapa 1 aponta que o controle é mais frágil na franja periférica, justamente onde a presença do poder público é menor e as vulnerabilidades socioambientais são maiores. Atualmente, os territórios de exclusão correspondem a $48 \%$ da área do município e as respectivas subprefeituras detêm somente $19 \%$ dos técnicos municipais (PEREIRA, 2010). Nas entrevistas fechadas aplicadas aos técnicos municipais, $74 \%$ concordaram que "se faz pouca ação fiscal nos territórios de exclusão, apenas nos casos de denúncia” (KEPPKE, 2007, p. 316).

Portanto, não por acaso, os territórios relegados à política habitacional da autoconstrução e à omissão da Fiscalização, são atualmente o objeto central da política de regularização fundiária do Estatuto da Cidade, ora mapeados como Zonas Especiais de Interesse Social

De outra parte, confirmando a lógica da "teoria da janela quebrada" (WILSON, KELLING, 1982), as irregularidades edilícias de uso e ocupação do solo acumularamse não apenas nos territórios de exclusão, mas se banalizaram também nos territórios de inclusão social, encorajando uma "estranha aliança" que periodicamente pressiona por anistia junto ao Poder Executivo e ao Parlamento (CAMPOS F., 2003). No momento, as expectativas crescem após quase dez anos da última anistia e em face do precedente legal para o licenciamento condicionado de caráter provisório.

\section{POR UMA PRÁTICA DE REGULARIZAÇÃO COM "RESPONSABILIDADE SOCIOAMBIENTAL"}

A falta de Fiscalização permitiu ocorrer a "tragédia dos comuns" (HARDIN, 1968): cada "puxadinho", cada abuso construtivo satisfez uma necessidade individual de moradia ou um comportamento "rent seeking" dos "players" do mercado e o resultado agregado foi a deterioração urbano-ambiental da cidade como um todo, onde cada cidadão perde qualidade de vida. 
Longos deslocamentos, congestionamentos diários, inundações sazonais, assentamentos precários por vezes somados a riscos geológicos incorporam-se ao estilo de vida do paulistano e aos prejuízos para a economia e a saúde pública sem que estado e sociedade reconheçam seu comportamento deletério de parcelamento, uso e ocupação do solo.

Segundo Kotler e Roberto (1992), a mudança do comportamento coletivo requer incentivos positivos e negativos. A possibilidade de regularização pode acenar como uma prática inevitável em face da proporção tomada pelas irregularidades, mas pode conduzir estado e sociedade para um novo pacto urbano-ambiental, caso o infrator pague o ônus pelos impactos causados.

De acordo com a teoria da regulação, o benefício do descumprimento de um contrato não pode ser maior do que o benefício do cumprimento (VISCUSI ET. AL, 1995, p. 727), do contrário, não haveria motivação para honrá-lo. A impunidade das infrações foi o antiexemplo das anistias anteriores e a razão da banalização das irregularidades.

Assim sendo, modelos para uma anistia com responsabilidade socioambiental deveriam:

I. Não anistiar as multas por irregularidades.

II. Identificar, responsabilizar, internalizar e onerar o impacto das infrações de parcelamento, uso e ocupação do solo contra o ambiente urbano-ambiental. A oneração deveria ter caráter progressivo, considerando as desigualdades sociais.

III. Atrelar o investimento dos recursos financeiros oriundos da anistia em obras e serviços públicos de reparação de danos, mitigação ou compensação de impactos urbano-ambientais.

Um primeiro ato administrativo de responsabilidade fiscal, em conformidade à lei complementar n.101 de 4 de maio de 2000, seria não anistiar nem abrandar as multas devidas pelas irregularidades. Para evitar a inadimplência, os valores poderiam sofrer descontos, parcelamentos ou agregação ao IPTU ${ }^{1}$, mas jamais anistiados. Desafortu-

\footnotetext{
${ }^{1}$ Imposto predial e territorial urbano
} 
nadamente, porém, a lei vigente diminuiu drasticamente o valor das sanções pecuniárias em relação à legislação anterior. Além disso, ainda há casos omissos de regulamentação fiscalizatória, por exemplo, para os usos residenciais e as incomodidades urbanas (odor, vibração, carga e descarga, emissão de radiação).

Um segundo ato de responsabilidade fiscal e social seria cobrar pelo impacto urbano-ambiental gerado. Em sendo possível associar os impactos aos seus agentes causadores, seria cabível tomar emprestado o princípio do poluidor pagador (BENJAMIN, 1993). Infrações relevantes tais como impermeabilização excessiva do solo, prejuízo à iluminação e ventilação natural própria e dos vizinhos são causados por excessos construtivos que poderiam ser individualmente mensurados e internalizados aos seus responsáveis.

Mas, na ausência de simuladores precisos ou, em nome da simplificação, aos excessos construtivos poderia ser aplicado o instrumento da outorga onerosa do direito de construir. Esta seria uma nova aplicação para o instrumento urbanístico, no caso, para fins de regularização edilícia, para efeito de compensação urbanístico-ambiental. Em caráter ilustrativo, segue abaixo uma sugestão que aplica a mesma fórmula já utilizada pelo Plano Diretor Estratégico (lei municipal 13.430 de 13 de setembro de 2002, complementada pela lei 13.885 de 25 de agosto de 2004):

$$
O_{r e}=F_{s}\left[\left(E_{c c} \times V_{v c}\right)+\left(E_{c t} \times V_{v t}\right)\right]
$$

Onde:

$\mathrm{O}_{\mathrm{re}}$ : outorga onerosa para fins de regularização edilícia

$\mathrm{F}_{\mathrm{s}}$ : Fator de dedução para fins de equidade social conforme estabelecido por distrito na lei municipal 13.885 de 25 de agosto de 2004; seu valor varia de 0 a 1; deduções totais $\left(F_{s}=0\right)$ seriam admissíveis nas Zonas Especiais de Interesse Social - ZEIS

$\mathrm{E}_{\mathrm{cc}}$ : área correspondente aos excessos construtivos computáveis, de acordo com o coeficiente de aproveitamento básico da zona de uso.

$\mathrm{V}_{\mathrm{vc}}$ : valor venal correspondente ao $\mathrm{m}^{2}$ construído, conforme a Planta Genérica de Valores.

$\mathrm{E}_{\mathrm{ct}}$ : área correspondente aos excessos de projeção edilícia, em relação à taxa de ocupação da zona de uso.

$\mathrm{V}_{\mathrm{vc}}$ : valor venal correspondente ao $\mathrm{m}^{2}$ do terreno, conforme a Planta Genérica de Valores. 
Finalmente, para efetivar a responsabilidade socioambiental, os recursos extraorçamentários captados com a outorga onerosa para fins de regularização edilícia deveriam ser atrelados ao Plano Diretor e aos Planos Regionais Estratégicos, priorizando as ações reparadoras, mitigatórias e compensações urbanístico-ambientais. Especial atenção teriam a drenagem, a recuperação do sistema de áreas verdes e a recomposição do estoque fundiário público necessário à política urbana e à reorientação da cidade aos princípios da sustentabilidade.

O expediente da compensação urbanística, sanitária e ambiental já vem sendo aplicado para fins de regularização dos assentamentos nas Áreas de Proteção e Recuperação dos Mananciais da Região Metropolitana de São Paulo (SÃO PAULO, ESTADO, 2006, 2009; SILVA, 2002), semeando uma nova cultura legislativa de responsabilidade socioambiental que pode ser aproveitada no previsível evento de anistia da cidade de São Paulo. Neste sentido, a sociedade encontra-se pressionada a ser sensibilizada pelo caos - caos do trânsito, caos das inundações, e pode aderir a pactos urbanoambientais mais ousados e "verdes", de responsabilidade compartilhada entre o ente público e o ente privado. 


\section{REFERÊNCIAS}

BENJAMIN, A. H. V. O princípio poluidor-pagador e a reparação do dano ambiental. In: __ Dano ambiental: prevenção, reparação e repressão. São Paulo: Revista dos Tribunais, 1993. p. 226-236. Disponível em: <http://bdjur.stj.gov.br/dspace/handle/2011/8692>. Acesso em: 23/09/2012.

BONDUKI, N. G. (1998) Origens da habitação social no Brasil arquitetura moderna, lei do inquilinato e difusão da casa própria. São Paulo, Estação Liberdade.

BRASIL, Presidência da República (1979) Lei n. 6.766, de 19 de dezembro de 1979. Dispõe sobre o Parcelamento do Solo Urbano e dá outras Providências. Disponível em http://www.planalto.gov.br/ccivil_03/leis/l6766.htm, acesso em 23/09/2012.

BRASIL, Presidência da República (2000) Lei n. 101 de 4 de maio de 2000. Estabelece normas de finanças públicas voltadas para a responsabilidade na gestão fiscal e dá outras providências. Disponível em: http://www.planalto.gov.br/ccivil_03/leis/lcp/ Icp101.htm, acesso em 23/09/2012.

BRASIL, Presidência da República (2001) Lei n. 10.257, de 10 de julho de 2001. Regulamenta os arts. 182 e 183 da Constituição Federal, estabelece diretrizes gerais da política urbana e dá outras providências. Disponível em: http://www.planalto.gov.br/ ccivil_03/leis/leis_2001/l10257.htm, acesso em 23/09/2012CAMPOS F., C. M. (2003) Reinvente seu Bairro: Caminhos para Você Participar do Planejamento de sua Cidade. São Paulo, Editora 34.

GROSTEIN, M. D. (1987) A Cidade Clandestina: os Ritos e os Mitos, o Papel da "Irregularidade" na Estruturação do Município de São Paulo, 1900-1987. São Paulo, 1987. Tese (Doutorado) - FAUUSP. Orientador: Candido Malta Campos Filho.

HARDIN, G. (1968). The tragedy of the commons. Science 162: 1243-1248.

KEPPKE, R. S. (2007) São Paulo, as Deseigualdades Sociais e o Descontrole de Uso e Ocupação do Solo, São Paulo, 2007. Tese (Doutorado) - FAUUSP. Orientador: Ricardo Toledo Silva.

KEPPKE, R. S.; SILVA, R. T. (2012) Controle Urbanístico-ambiental em São Paulo, Riscos e Oportunidades in Arquiteses 3, São Paulo, FAUUSP, no prelo. 
KINGDON, J. W. (1995) Agendas Alternatives and Public Policies. (revised 2nd. Edition). New York: Harper-Collins.

KOTLER. P.; ROBERTO, E. L. (1992) Marketing Social: Estratégias para Alterar o Comportamento Público. Tradução de José Ricardo Azevedo e Elizabethe Maria Braga. Rio de Janeiro, Campus.

PEREIRA, O. M. A. (2010) PMSP: Carreiras de Engenharia e Arquitetura, Decadência e Reflexos no Desenvolvimento Urbano. Trabalho de Conclusão do Curso de Pósgraduação em Gestão Pública da Universidade Mogi das Cruzes, orientadora: Profa. MsC Maria das Graças Ferreira.

SAMPAIO, M. R. A. (2002) A promoção privada de habitação econômica e a arquitetura moderna 1930-1964. São Carlos, SP RiMA.

SÃO PAULO, Cidade (1913 a 2004). Leis municipais disponíveis em www.prefeitura. sp.gov.br, acesso em 17/09/2012.

SÃO PAULO, Estado (2006). Lei estadual n 12.233, de 16 de janeiro de 2006. Define a Área de Proteção e Recuperação dos Mananciais da Bacia Hidrográfica do Guarapiranga, e dá outras providências correlatas. Disponível em http://www.sigam.ambiente. sp.gov.br/sigam2/Repositorio/259/Documentos/12233.pdf, acesso em 17/09/2012

SÃO PAULO, Estado (2009). Lei estadual 13579 de 13 de julho de 2009. Define a Área de Proteção e Recuperação dos Mananciais da Bacia Hidrográfica do Reservatório Billings - APRM-B, e dá outras providências correlatas. Disponível em http://www. ambiente.sp.gov.br/legislacao/estadual/leis/2009_lei_13579.pdf, acesso em 17/09/2012

SILVA, R. T. (2002) São Paulo: Instrumentos de Planejamento Metropolitano e Gestão Integrada de Recursos Hídricos disponível em http://www.fau.usp.br/docentes/ deptecnologia/r_toledo/3textos/SP_gestao_integrada_R2F.pdf, acesso em 17/09/2012 VISCUSI W.; VERNON, J.; HARRINGTON JR., E. (1995) Economics of regulation and antitrust. Second edition, Massachusets Institute of Technology.

WILSON, J.; KELLING, G.. (1982) Broken Windows: the police and the neighborhood safety. The Atlantic Monthly, mar/1982. Disponível em <http://www.theatlantic.com/ magazine/archive/1982/03/broken-windows/4465/> Acesso em 31/10/2012. 